\title{
Correction to: Trends in the diabetes incidence and mortality in India from 1990 to 2019: a joinpoint and age-period-cohort analysis
}

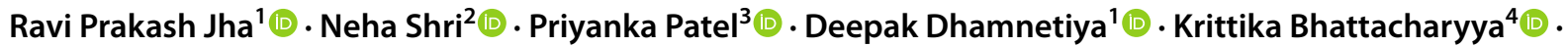 \\ Mayank Singh ${ }^{5}$
}

Published online: 12 August 2021

๑) Springer Nature Switzerland AG 2021

\section{Correction to: Journal of Diabetes \& Metabolic Disorders https://doi.org/10.1007/s40200-021-00834-y}

The references have been updated. The original article has been corrected.

Publisher's note Springer Nature remains neutral with regard to jurisdictional claims in published maps and institutional affiliations.

The original article can be found online at https://doi.org/10.1007/ s40200-021-00834-y.

Mayank Singh

singhmayank.251195@gmail.com

Ravi Prakash Jha

ravijha0292@gmail.com

Neha Shri

nshri793@gmail.com

Priyanka Patel

patelpriyankacsb@gmail.com

Deepak Dhamnetiya

drdeepakdhamnetiya@gmail.com

Krittika Bhattacharyya

krittikabhattacharyya.federer@gmail.com
1 Department of Community Medicine, Dr. Baba Saheb Ambedkar Medical College \& Hospital, 110085 Delhi, India

2 International Institute for Population Sciences (IIPS), Mumbai 400088, India

3 Department of Development Studies, International Institute for Population Sciences (IIPS), Mumbai 400088, India

4 Department of Statistics, University of Calcutta, Kolkata 700019, India

5 Department of Fertility Studies, International Institute for Population Sciences (IIPS), Mumbai 400088, India 